\title{
Challenges of SOA adoption in the Telco domain for Latin American researchers
}

\author{
Desafíos de la adopción de SOA en el dominio Telco para los \\ investigadores latinoamericanos
}

\section{Desafios da adoção de SOA no domínio Telco para os pesquisadores latino-americanos}

\section{Abstract}

Telecommunication service providers such as Mobile Network Operators are currently under the vortex arising from paradigm shifts imposed by the omnipresence of the Internet. The adoption of Service Oriented Architecture and the shift to Next Generation Networks constitute some of the efforts of these organizations at the confluence toward these new business models. This article introduces a review of the concepts behind these proposals within Telco organizations, identifies gaps and discusses about the challenges that research and development groups are facing in the Latin American context; obstacles to overcome for converging and creating a synergic environment of common interests oriented to the innovation around the subject.

Keywords: SOA, NGN, NGOSS, SDP, Cloud Computing.

\footnotetext{
* M.Sc. (c) Universidad del Cauca (Popayán-Cauca, Colombia). fmendioroz@unicauca.edu.co.

** Ph.D. Universidad del Cauca (Popayán-Cauca, Colombia). arendon@unicauca.edu.co.

*** Ph.D. Universidad del Cauca (Popayán-Cauca, Colombia).jcorral@unicauca.edu.co.

**** M.Sc. Universidad del Cauca, (Popayán-Cauca, Colombia). jarojas@unicauca.edu.co.
} 


\section{Resumen}

Las organizaciones proveedoras de servicios de telecomunicaciones, tales como los operadores de redes móviles, se encuentran hoy en día bajo la vorágine que representan los cambios de paradigma impuestos por la omnipresencia de Internet. La adopción de la Arquitectura Orientada a Servicios y el desplazamiento hacia Redes de Próxima Generación, constituyen parte de los esfuerzos de estas organizaciones en la confluencia hacia estos nuevos modelos de negocio. El presente artículo efectúa una revisión de los conceptos detrás de estas propuestas al interior de las grandes organizaciones de telecomunicaciones, identifica brechas y discute sobre las dificultades a las que se enfrentan los grupos de investigación y desarrollo en el contexto latinoamericano; obstáculos a superar a efectos de converger y crear un ambiente sinérgico de intereses comunes hacia la innovación alrededor de la temática.

Palabras Clave: SOA, NGN, NGOSS, SDP, Cloud Computing.

\section{Resumo}

As organizações provedoras de serviços de telecomunicações, tais como os operadores de redes móveis, encontramse hoje em dia sob a voragem que representam as mudanças de paradigmas impostos pela omnipresença da Internet. A adoção da Arquitetura Orientada a Serviços e o deslocamento para Redes de Próxima Geração, constituem parte dos esforços destas organizações na confluência para estes novos modelos de negócio. O presente artigo efetua uma revisão dos conceitos por trás destas propostas ao interior das grandes organizações de telecomunicações, identifica brechas e discute sobre as dificuldades às que se enfrentam os grupos de pesquisa e desenvolvimento no contexto latino-americano; obstáculos a superar efeitos de convergir e criar um ambiente sinérgico de interesses comuns para a inovação ao redor da temática.

Palavras Chave: SOA, NGN, NGOSS, SDP, Cloud Computing.

Cómo citar este artículo:

[1] F. Mendioroz-Cotelo, A. Rendón-Gallón, J.C. Corrales-Muñoz \& J.A. Rojas-Meléndez, "Challenges of SOA adoption in the Telco domain for Latin American researchers", Fac. Ing., vol. 24 (39), pp. 9-19, MayoAgo. 2015. 


\section{INTRODUCTION}

SOA (Service-Oriented Architecture) [1] model adoption within a telecommunication organization (hereinafter referred to as «Telco») is closely related to NGN (Next Generation Networks) [2] deployment. NGN design and boost comes after the understanding of the limitations imposed by legacy fixed and mobile Intelligent Networks (IN/CAMEL [3-4]) regarding third parties collaboration for service creation and decoupling from the network infrastructure, along with less time to market. NGN provide MNOs (Mobile Network Operators) able to share resources and infrastructure, enable network interoperability, simplify and merge management, operation and maintenance of the offer, thus allowing swift and costeffective creation of new and custom-made ubiquitous wideband services. These new facilities allow third parties to take advantage of telecommunications capabilities within their own development environments. Likewise, final customers can find new services previously banned due to legacy networks' transmission latency, weak performance, etc.

The telecommunication networks management models also need a transformation, adjusting and embracing this evolution imposed by the NGN deployment under SOA paradigms. Standardization organizations such as TM Forum [5] and ITU-T [6] converge in NGN management under the acronym NGOSS (New Generation Operation Systems and Software). Between 1995 and 1996, TM Forum matures the TOM (Telecom Operations Map) concept, which evolves itself into eTOM [7] (enhanced TOM), released under ITU-T Recommendation M.3050 series, replacing the TMN (Telecommunications Management Network) way under ITU-T Recommendation M.3010. The main difference between eTOM and TMN relies on management approach; while TMN was built upon network architecture and infrastructure management requirements (bottom-up), eTOM basement relies on the need of global support for the entire processes inward the service provider organization (top-down). eTOM focus resides on business processes used by service providers, relationships among procedures, interfaces identification and usage from multiple processes of information about clients, services, resources, providers and associates. eTOM relates with other standards and frameworks which include specially SOA and ITIL $\circledR$ [8].

At the same time, the successful deployment of services based on Cloud Computing [9], finished to setting up the paradigm shift scenario which establishes a huge challenge for Telcos.

Based on implementation outcomes widely published, along with the experiences collected from the business of Value Added Services (VAS) platform providers for Telcos in the Latin American context throughout the last decade, this paper identifies the complexities faced by the Telco ecosystem which comprise MNOs, universities, enterprises, public entities, development corporations, etc., in their purpose for reaching the goals behind these new paradigms. The needing of a systemic approach is perceived, in order to adjust research and development (hereinafter referred to as «R\&D») practices in the pursuit of innovation, in the midst of a scenery in which ceaseless transformation is the rule. Simultaneously, differences and intricacies in the adoption of Cloud Computing practices inside Telcos are analyzed. In summary, existing gaps between the Latin American Telco ecosystem, and markets or regions leading the research, development and innovation in the subject are exhibited.

\section{Literature Review}

SOA constitutes a software engineering concept or paradigm for the manipulation and arrangement of distributed services running on diverse providers' implementations [10-14]. Before SOA, Telcos was following an architectural model of closed monolithic applications, where business roles depended on these hermetic silos. This tightly coupled model is pretty inefficient and brittle compared to SOA, in which a reusable services oriented system is promoted by applications and business rules alignment. SOA offers a lot of principles for the construction of complex, loosely coupled, autonomous and granular applications. Likewise, it also defines patterns for the composition of self-described services, in order to accomplish interoperability between software platforms, as well as dynamic interaction among business processes. 
SOA proposal consist of reducing complexity for apps integration through a single platform and a programming language, independent from service layer. Apps like account management, order processing and scheduling, etc., corresponds under SOA to functions that follow rules of compound business processes and service reuse. This horizontal scheme is much more open, efficient, resilient, integrated, interoperable and collaborative. The integrity of billing data, CRM (Customer Relationship Management) [15], DWH (Data Warehouse), etc., is more assured in this way, and therefore a positive impact on the IT (Information Technologies) domain is granted in both efficiency and effectiveness.

A SDP (Service Delivery Platform) (Figure 1) can be defined as an IT mediation platform under the SOA paradigm, or simply an «IT SOA Middleware», built with performance and capabilities inherent of telecommunications implementations [16]. An appropriate SDP architecture is provided by OSE (OMA Service Environment) [17], as well as the technical specifications and enactments related to OMA (Open Mobile Alliance) and ITU-T.

Several initiatives have developed specifications for interconnecting service enabling functionalities, such as OSE, JAIN SLEE (Java APIs for Integrated Networks Service Logic Execution Environment) [18], RCS (Rich Communications Services) [19] from GSMA (GSM Association), etc. These proposals trust in strong established paradigms, such as object oriented components, besides adding distinctive characteristics from telecommunications, such as asynchronous events interactions and transactional models.

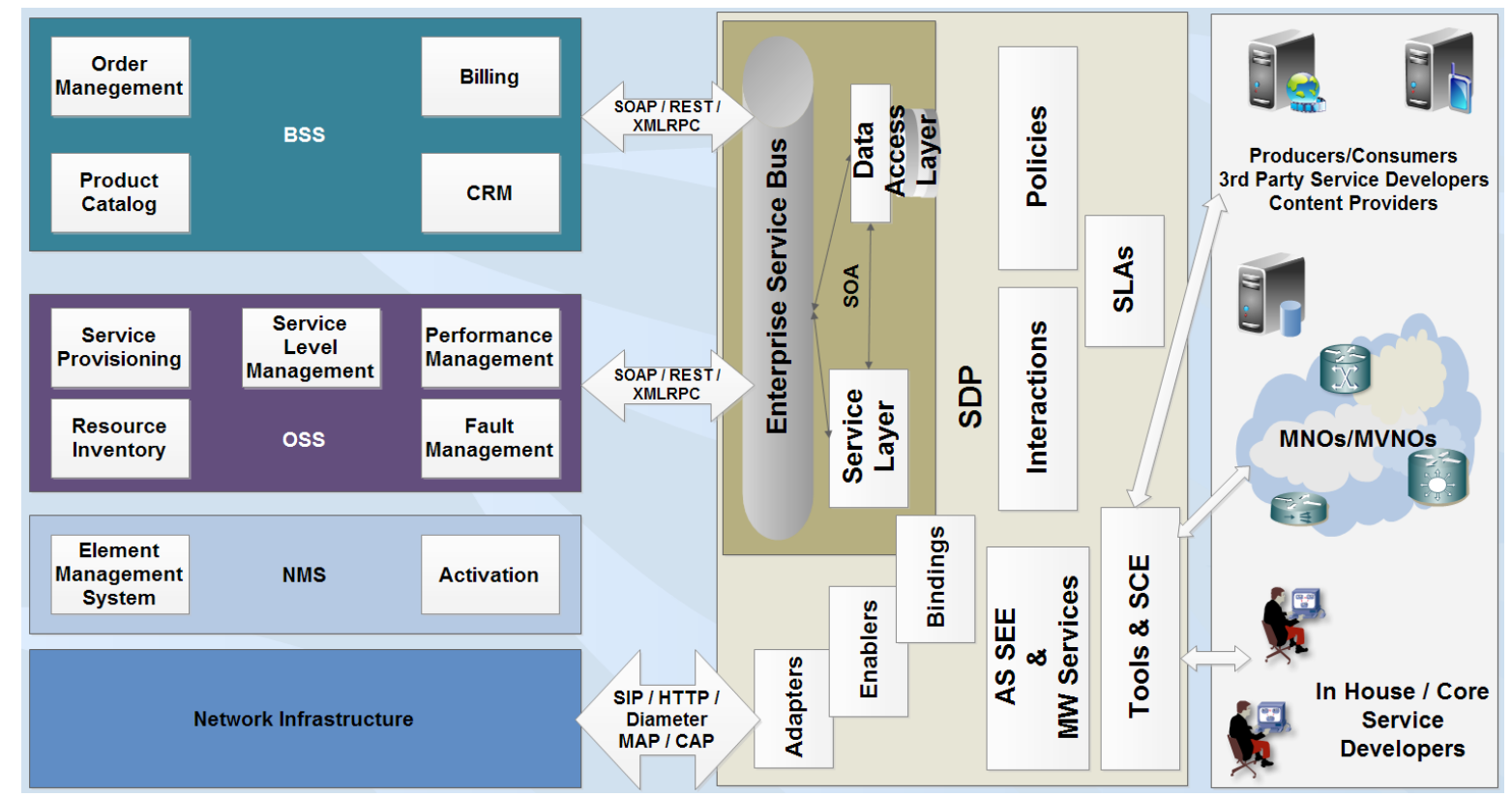

Fig. 1. SDP integrated into a Telco organizational environment under the SOA paradigm.

In a Telco environment, it's vital that an SDP provides communication functions so as to offer an abstraction of the underlying network capabilities to a Service Creation Environment (SCE). As shown in Figure 1, a relationship between the network infrastructure and either own or third parties developers is established by the intermediate SDP through «Adapters», «Enablers» and «Bindings». JAIN SLEE Resource Adaptors (RA) have been developed with this purpose. Diverse projects suited to JAIN SLEE specification have assembled and complemented resource adaptors for the control plane of switched circuit networks (i.e., RA MAP, RA CAP, RA ISUP, etc., distinctive of legacy mobile networks such as GSM), as well as those of packet switched networks (i.e., RA SIP, RA Diameter, etc., representative of NGN implementations). An SDP provided with resource adaptors, such as JAIN SLEE's RAs, exposes underlying network capabilities through «Enablers» that control those capabilities via the RAs. By these means, the conjunction of adapters, enablers 
and Service Creation/Execution Environments (SCE/ SEE) like the kind of a typical SIP Application Server (SIP AS) specified by UMTS IMS (IP Multimedia Subsystem) [20], or a Service Control Function inherent of a Signaling Control Point (gsmSCF/SCP) from legacy networks such as GSM, provide an SDP of powerful communication abilities. Hence, in-house or third parties' developments are fulfilled through the composition of enablers or within the SEE/SCE, independently of the underlying network technology or equipment, with capabilities of short and instant messaging services (SMS, USSD, IM, etc.), call or mobile Internet navigation control, etc. These abilities are widely used in the development of multiple VAS such as subscriptions, promotions, mobile payments, transfers and remittances, emergency alerts, account balance inquiries, etc.

The enablers may be also used for exposing apps from the telecommunications network core, e.g., those from the OSS/BSS (Operating/Business Support System) layer such as CRM, Billing, Order Management, Fault Management, Performance Management, etc. [16]. The SDP networks with the OSS/BSS and NMS (Network Management System) through an Enterprise Service Bus as exposed in Figure 1. Interfaces use to place Web/Link Services (SOAP and/or REST [21]), whereas the SDP grants a controlled exposure through the enforcement of policies and SLAs (Service Level Agreements) [22] at every request or response from and to the enablers and containers.

Moreover, the user-centric platforms, built on user needs and requirements, along with the leverage of Web 2.0 technologies, have boosted the role of the so called «prosumers» (producers/consumers), non-expert users which can create and share their own created services. The main concept behind these user-centric platforms is the so called «mashup», which constitutes small apps built through the composition of two or more services and contents. Since homogeneous interfaces are available for NGN services, the «prosumers» became able to combine within their mashups the traditional Telco functionalities alongside with Web 2.0 specific services. Additionally, as a result of those standard interfaces, service delivery can leverage support tools from Web 2.0 like recommendations, profiles, user contacts, social networks, etc.
In line with the aforementioned technological paradigm shifts, the European Union promoted the realization of joint projects involving academic institutions and Telcos, which included studies around SOA paradigm and user-centric platforms. One of those projects, named OPUCE [23] (Open Platform for User-centric service Creation and Execution), built a SDP for telecommunications by merging IT and NGN services, making accessible to the users the mashup services creation. Other highlighted projects, analogous to OPUCE and also financed by the European Union were OMELETTE [24] (Open Mashup Enterprise service platform for LinkEd data in The TElco domain) and AKOGRIMO [25] (Access to Knowledge through the Grid in a Mobile World). OMELETTE counted with the participation and sponsorship of several academic institutions, such as UNITN from Trento, Italy; TUC from Chemnitz Germany; UPM from Madrid Spain; UNIBOL from Bolton, United Kingdom; along with large Telcos and IT companies like Huawei from China, TIE Kinetic from the Netherlands, T-Systems and SAP from Germany. Meanwhile, AKOGRIMO was implemented in a joint work by the Stuttgart University from Germany (where the platform core and specific services were placed) and UPM from Madrid (where users equipment and access routers where located), together with the Spanish corporation Telefónica I+D. Other similar projects may be found in [26-31], also accomplished under the European Union sponsorship, or from Asia and, particularly, China. All these SDP implementations under SOA concepts show with nuances a related model, namely:

- A «prosumer-friendly» SCE, normally available in the Web;

- A SEE (Service Execution Environment) for services developed within the SCE, which constitutes a classic SOA middleware, where is typically observed what's following:

- Composition (orchestration and choreography) engines of business processes, based on programming languages such as BPEL [32-34], PNML [35], OWL [36], etc.

- An event oriented service execution container or engine for the Telco domain (encompassed by ad-hoc implementations or based on JAIN 
SLEE specification like TeleStax' Mobicents open source project [37]).

- An ESB (Enterprise Service Bus) [38-40], intermediary between the composition engine and the Telco event oriented services execution engine.

- Well defined interfaces specified in WSDL [4142] (Web Services Description Language) for the exposure of the services and interoperability with other systems through SOAP, REST, etc.

In the meantime, there is a clear breakup in Latin America between the different actors who indeed are promoting this type of R\&D activities in the European, South-East Asian and North American context, i.e., Telco operators, universities, business entrepreneurship related to VAS SDP development and governmental or regional integration organizations. Moreover, precious few graduate programs addressing this approach are found in this region. Likewise, any attempt from these few universities addressing this approach, gets a boost from virtually none stakeholder (i.e., Telcos or service providers). Against this backdrop, the motivation of professionals and researchers behind this subjects is severely impacted in the opposite sense to the one founded by their European counterparts of OPUCE, OMELETTE and AKOGRIMO projects. What makes worse this outlook, is that the scarce R\&D efforts carried out in this unfavorable context, such as the TelComp 2.0 project financed by Colciencias [43], on one hand they still do not manage to catch the needed interest of significant Telco players and, on the other hand, the reported experiment executed in the environment of a small regional operator, where it was feasible to carry out drills and tests of the developed prototype, still found operative difficulties due to the absence of adaptation to SOA and NGN principles of the operator networking infrastructure. In these circumstances, the current motivation for greater efforts in the continuance of $R \& D$ projects like the above, relapses on the dilemma of whether it is viable.

Along with the context presented until now, the hype around the success and promises of Cloud Computing, SDN (Software Defined Networking) and NFV (Network Function Virtualization), sponsored among others, by big enterprises such as Amazon, Google, Yahoo, Salesforce and Microsoft, as well as the offers of significant organizations such as IBM, Oracle,
VMWare, Cisco, Ericsson, Intel, HP, Metaswitch Networks and many open source projects like Project Clearwater, must be tackled as it is in fact nowadays a significant concern for TELCO. Because of this, today many of the latter companies, along with SDP providers, are encompassing initiatives, essays, trials, and commercial services already in the Cloud, as the ones exposed in [9, 44-46].

\section{GAPS}

All of the works analyzed until this point, constitute a big effort towards the solution of the challenges faced by Telcos in order to meet the expectations around services in the way Internet does with the Web 2.0 archetype, through what could be called Telco 2.0 platforms, encompassing NGN and SOA guidelines. However, dynamic development of solutions in the domain of Internet fits much looser features than those needed to follow within classic Telco organizations such as an MNO. Strict regulations, specifications, contracts, security governance, etc., impose development and innovation times in the Telco domain significantly higher than those for the Internet.

Neither the referenced works in this paper, nor the known offer of the VAS platforms providers in the Latin American context, mentions any compliance of the TM Forum's or ISO 2000 specifications, in order to pursuing eTOM's and ITIL $\AA$ [47] guidelines. A SDP that satisfies the TM Forum's and ISO 2000 specifications, so as to being compatible with eTOM

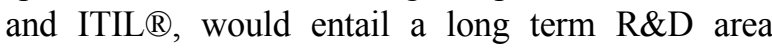
completely aligned under SOA and NGN paradigms. This fact does not turn out to be completely unexpected given the wrapped complexity and the need for permanent coaching of technical workforces for the widespread adoption of these frameworks within their organizations, so much of operators as providers. Moreover, the recent irruption of these paradigms, contemporary with NGN deployments such as UMTS IMS and LTE's Evolved Packet System [48], and SOA adoption at the Telco/IT domain [49], fulfills a comprehensive landscape with regard to the difficulties which this sector of the industry is facing.

Finally, Cloud Computing's phenomenon in the provisioning of services becomes a necessary matter at this point of the analysis. NIST (National Institute 
of Standards and Technology) defined the three levels of the «Cloud Stack» [9], that is: SaaS (Software as a Service), specified as the provisioning of an application -typically a Web Service-; PaaS (Platform as a Service), established as the provision of a platform and associated tools for service creation according to a service model; and IaaS (Infrastructure as a Service), base for Cloud stack, determined for the delivery of computing resources such as virtual machines, storage, networking and other resources according to a service model. Although services creation environments offered to the users contemplate proposals accordingly to SaaS and PaaS essentials, this is anything but trivial or even feasible within Telco's ecosystems. Service creation carried out by inner or hired qualified personnel is what normally fits inside Telco environments. This circumstance is certain because of the complexity of following in these scenarios the «prosumers» model of the Web 2.0, given an almost null fault tolerance and quality of service requisites of a Telco organization and, at once, the governance guidelines imposed to these organizations, for instance, those provided by SOX (Sarbanes-Oxley Act) [50]. A possible action line would be similar approaches as the one given by [27], i.e., extend programming languages like WSDL, BPEL, PNML, OWL, etc., for services composition engines of VAS platforms, in order to shield the Telco operator against flaws in the development and deployment of these services in a stage of Cloud implementation. Nevertheless, considering the restrictions and controls of a Telco operator, as well as the enormous complexity that involves putting in operation a service in this environment, in practice, this last proposal is not feasible. Hence the model must follow some different guiding principles from those traditional of the Web 2.0. Although some trials or implementations have been carried out by Vodafone, Telefonica, Telecom Italia, Orange and T-Mobile, as detailed in [45], where Cloud Computing model in this environment is said to turn out to be closer to PaaS than SaaS approach, the expected limitations imposed by Telco operators, already identified here, are confirmed.

\section{Conclusions y Proposals}

From the literature revision and gaps disclosed in the previous section, together with well-known state of the art regarding VAS platform deployment throughout the Latin American Telco landscape, there is a clear evidence of a drop behind in matter of R\&D around NGN and SOA. In contrast to the aforementioned projects financed by the European Union, similar initiatives are not known among Telco organizations, companies and universities financed by similar organisms, such as the Inter-American Development Bank or state dependencies.

In this scenario, it is not surprising that the latest Ericsson Mobility Report [51] is showing a clear lag in the stats of the Latin American mobile telecommunications market compared to the European, North American and Asia-Pacific ones. The predictions for 2018 show a very low relative breakthrough in the matter of deployment and subscriptions to next generation services and networks. From this report, there is also clear the need for VAS SDP developments harmonizing the progress of NGN, based just on packet switched networks over IP, aside with transient continuity of circuit switched legacy networks.

However, there are likelihoods to find support for the research, development and innovation in the area of Information and Communications Technologies (ICT), mainly in the programs developed by the Department of ICT of Colombia (MinTIC), in conjunction with Colciencias, as well as the resources of the recently created General System of Royalties. With MinTIC's support, looking forward to sow a similar ecosystem to the one promoted by the European Union is somewhat not so unattainable. The authors of this paper encourage stakeholders to dedicate efforts to feed this ecosystem and by that, ease possible alliances with the largest national Telco organizations such as MNOs, as well as companies from the private and entrepreneurial sector.

The TelComp2.0 project continues with nuances the guidelines of the SDPs related to the European projects described above. For giving continuity to this work, broaden its scope is proposed here, thus giving support to the creation of services supported simultaneously and transparently either on circuit switched legacy networks developed over the Signalling System No. 7 (SS7) protocol stack (i.e., MAP [52], CAP [53], etc.), or on packet switched signalling protocols of NGNs like the IMS or LTE (i.e., SIP [54], Diameter [55], etc.). Besides, taking as a motivation scenario the recent regulation from Colombian Communications Regulation Commission (CRC) regarding the 
provisioning of mobile financial services throughout the country [56], which must include the offer of USSD as one of its communication channels [5759], and concurrently, the implementation of the National Emergency Telecommunications Network (RNTE) for LTE [60], the continuity of the research and development work in this field becomes attractive, approaching the existing breaches in the specifications and enabling the deployment of certain NGN services, namely:

- Voice over LTE (VoLTE) [61], is yet under exploration and deployment (almost all LTE networks in production are still using circuit switched legacy networks for voice call establishment and continuousness, procedures like CSFB after «Circuit Switch Fall-Back» and SRVCC after «Single Radio Voice Call Continuity»)

- Location Based Services (LBS) according to 3GPP/LTE specifications regarding Diameter signalling for LTE [62];

- USSD services for the IMS and LTE over SIP [59], given the lack of matureness and conclusion of the involved 3GPP technical specification, and thus, the inexistence of this kind of deployments within LTE. This would provide transparent continuity to the already implemented VAS based on USSD for legacy networks, without the need for install costly applications (e.g., the one provided by «USSDx» platform in conjunction with the «emDial» mobile application from Balefyre [63], only known implementation of USSD over IP in commercial service).

\section{REFERENCES}

[1] J. Kress, B. Maier, H. Normann, D. Schmeidel, G. Schmutz, B. Trops, C. Utschig-Utschig and T. Winterberg. (2013, July). Industrial SOA [Online]. Available: http://www.oracle.com/ technetwork/articles/soa/ind-soa-toc-1934143. html. [Accessed: 23-Sep-2014].

[2] C. Lee. (2009, May). Architectural Overview of ITU-T NGN (including Future Vision). In: Next Generation Networks and Applications, Athens,
Greece [Online]. Available: http://www.itu.int/ ITU-T/worksem/ngn/200905/. [Accessed: 23Sep-2014].

[3] R. Noldus, CAMEL Intelligent Networks for the GSM GPRS and UMTS Networks, West Sussex, England, Wiley, 2006.

[4] E. S. Chaniotakis, A. E. Papadakis and I. S. Venieris, "External service provision in telecommunications networks using open interfaces," Computer Communications, vol. 27, no. 1, pp. 1-12, Jan. 2004.

[5] "TeleManagement Forum." [Online]. Available: http://www.tmforum.org/. [Accessed: 23-Sep2014].

[6] Principles for the Management of Next Generation Networks, ITU-T Recommendation M.3060/Y.2401, 2013.

[7] Cisco Systems. (2009). Introduction to eTOM White Paper [Online]. Available: http://www. cisco.com/c/en/us/products/collateral/services/ high-availability/white_paper_c11-541448.pdf. [Accessed: 23-Sep-2014].

[8] ITIL $\AA .(2014)$, Welcome to the official ITIL $\AA$ website. [Online]. Available: http://www.itilofficialsite.com/. [Accessed: 23-Sep-2014].

[9] J. S. Ward and A. Barker, "A Cloud Computing Survey: Developments and Future Trends in Infrastructure as a Service Computing," arXiv:1306.1394 [cs], Jun. 2013.

[10] S. Talja, "Service-Oriented Process Models in Telecommunication Business," M.S. thesis, The Department of the Computer Science, The University of Helsinki, Helsinki, 2013.

[11] J. Schelp and S. Aier, "SOA and EA-Sustainable Contributions for Increasing Corporate Agility," in 42nd Hawaii International Conference on System Sciences, 2009. HICSS '09, 2009, pp. $1-8$.

[12] H. Demirkan, R. J. Kauffman, J. A. Vayghan, H.-G. Fill, D. Karagiannis and P. P. Maglio, "Service-oriented technology and management: Perspectives on research and practice for the coming decade," Electronic Commerce Research and Applications, vol. 7, no. 4, pp. 356-376, 2008.

[13] T. Ishaya and M. Folarin, "A service oriented approach to Business Intelligence in Telecoms industry," Telematics and Informatics, vol. 29, no. 3, pp. 273-285, Aug. 2012. 
[14] J. Kress, B. Maier, H. Normann, D. Schmeidel, G. Schmutz, B. Trops, C. Utschig-Utschig and T. Winterberg, "SOA in Real Life: Mobile Solutions". [Online]. Available: http://www. oracle.com/technetwork/articles/soa/ind-soamobile-2045748.html. [Accessed: 23-Sep2014].

[15] N. H. M. Ariffin, A. R. Hamdan, K. Omar and N. Janom, "Customer Relationship Management (CRM) implementation: A soft issue in knowledge management scenario," in 2012 IEEE Colloquium on Humanities, Science and Engineering (CHUSER), 2012, pp. 485-489.

[16] S. H. Maes. (2010). Next Generation Telco Service Providers: Telco 2.0 and Beyond [Online]. Available: http://www.stephanemaes. com/ESSEM/Download/2010/Huawei_CTO_ paper_sm_7_5_10.pdf. [Accessed: $\overline{23}-\mathrm{Sep}-$ 2014].

[17] S. H. Maes, "Service Delivery Platforms as IT Realization of OMA Service Environment: Service Oriented Architectures for Telecommunications," in IEEE Wireless Communications and Networking Conference, 2007.WCNC 2007, 2007, pp. 2883-2888.

[18] D. Ferry, Open Cloud, Sun Microsystems Inc. (2008). JSR-000240 JAIN SLEE (JSLEE) 1.1 Specification Final Release [Online]. Available: https://jcp.org/aboutJava/communityprocess/ final/jsr240/. [Accessed: 23-Sep-2014].

[19] GSMA Rich Communications Suite. (2014), Rich Communications | Network 2020. [Online]. Available: http://www.gsma.com/network2020/ rcs/. [Accessed: 23-Sep-2014].

[20] G. Camarillo and M. A. García-Martín, The 3G IP Multimedia Subsystem (IMS) Merging the Internet and the Cellular Worlds, 3rd. ed., West Sussex, England, Wiley, 2008.

[21] W. Jiang, D. Lee and S. Hu, "Large-Scale Longitudinal Analysis of SOAP-Based and RESTful Web Services," in 2012 IEEE 19th International Conference on Web Services (ICWS), 2012, pp. 218-225.

[22] Z. Shu and S. Meina, "An architecture design of life cycle based SLA management," in 2010 The 12th International Conference on Advanced Communication Technology (ICACT), 2010, vol. 2, pp. 1351-1355.

[23] J. C. Yelmo, J. M. del Álamo, R. Trapero and Y. S. Martín, "A user-centric approach to service creation and delivery over next generation networks," Computer Communications, vol. 34, no. 2, pp. 209-222, Feb. 2011.

[24] O. Chudnovskyy, T. Nestler, M. Gaedke, F. Daniel, J. I. Fernández-Villamor, V. Chepegin, J. A. Fornas, S. Wilson, C. Kögler and $\mathrm{H}$. Chang, "End-user-oriented Telco Mashups: The OMELETTE Approach," in Proceedings of the 21st International Conference Companion on World Wide Web, New York, NY, USA, 2012, pp. 235-238.

[25] J. Jähnert, P. Mandic, A. Cuevas, S. Wesner, J. I. Moreno, V. Villagra, V. Olmedo and B. Stiller, "A Prototype and Demonstrator of Akogrimo's Architecture: An Approach of Merging Grids, SOA, and the Mobile Internet," Comput. Commun., vol. 33, no. 11, pp. 1304-1317, Jul. 2010.

[26] C. Bo, Z. Yang, Z. Peng, D. Hua, H. Xiaoxiao, W. Zheng and C. Junliang, "Development of WebTelecom Based Hybrid Services Orchestration and Execution Middleware over Convergence Networks," J. Netw. Comput. Appl., vol. 33, no. 5, pp. 620-630, Sep. 2010.

[27] M. B. Juric, "WSDL and BPEL extensions for Event Driven Architecture," Information and Software Technology, vol. 52, no. 10, pp. 10231043, Oct. 2010.

[28] C. Bo, C. Junliang and D. Min, "Petri Net Based Formal Analysis for Multimedia Conferencing Services Orchestration," Expert Syst. Appl., vol. 39, no. 1, pp. 696-705, Jan. 2012.

[29] H. Xu, M. Song, H. Chen and J. Song, "Research on SOA based mobile mashup platform for telecom networks," The Journal of China Universities of Posts and Telecommunications, vol. 15, Supplement, pp. 31-36, Sep. 2008.

[30] H. Wehbe and A. Bouabdallah, "A User-Centric Communication Model for Mobile Web," Procedia Computer Science, vol. 10, pp. 680687, 2012.

[31] C. Menkens, "From service delivery to application delivery in the telecommunication industry," in 2010 IEEE GLOBECOM Workshops (GC Wkshps), 2010, pp. 13391344.

[32] OASIS Web Services Business Process Execution Language (WSBPEL) TC. (2007, May 9). Web Services Business Process Execution Language Version 2.0 [Online]. 
Available: $\quad$ https://www.oasis-open.org/ committees/download.php/23964/wsbpel-v2.0primer.htm. [Accessed: 23-Sep-2014].

[33] A.VemulapalliandN. Subramanian, "Evaluating consistency between BPEL specifications and functional requirements of complex computing systems using the NFR approach," in 2010 4th Annual IEEE Systems Conference, 2010, pp. $153-158$.

[34] C. Ouvans, M. Dumas, A. H. M. Ter Hofstede and W. M. P. Van der Aalst, "From BPMN Process Models to BPEL Web Services," in International Conference on Web Services, 2006. ICWS '06, 2006, pp. 285-292.

[35] J. Billington, S. Christensen, K. van Hee, E. Kindler, O. Kummer, L. Petrucci, R. Post, C. Stehno and M. Weber, "The Petri Net Markup Language: Concepts, Technology, and Tools," in Applications and Theory of Petri Nets 2003, W. M. P. van der Aalst and E. Best, Eds. Springer Berlin Heidelberg, 2003, pp. 483-505.

[36] S. Zhao, P. Wongthongtham, T. Dillon and E. Chang, "Mapping relational data model to OWL ontology: Knowledge conceptualization in OWL," in 2nd IEEE International Conference on Digital Ecosystems and Technologies, 2008. DEST 2008, 2008, pp. 497-501.

[37] TeleStax. (2015). Open Source or Enterprise Grade. [Online]. Available: http://www.telestax. com/open-source/. [Accessed: 2-Apr-2015].

[38] A. T. Manes. (2007, Oct. 05) Enterprise Service Bus: A Definition. Burton Group [Online]. Available: http://i.i.cbsi.com/cnwk.1d/html/itp/ burton_ESB.pdf. [Accessed: 23-Sep-2014].

[39] I. Kumara and C. Gamage, "Towards Reusing ESB Services in Different ESB Architectures," in Computer Software and Applications Conference Workshops (COMPSACW), 2010 IEEE 34th Annual, 2010, pp. 25-30.

[40] M. Luo, B. Goldshlager and L.J. Zhang, "Designing and implementing Enterprise Service Bus (ESB) and SOA solutions," in 2005 IEEE International Conference on Services Computing, 2005, vol. 2, p. xiv vol.2-.

[41] W3C. "Web Services Description Language (WSDL) Version 2.0 Part 1: Core Language," 26-Jun-2007. [Online]. Available: http://www. w3.org/TR/2007/REC-wsd120-20070626/. [Accessed: 23-Sep-2014].
[42] S. Manan, H. F. Ahmad, S. Liaquat and H. Suguri, "Autonomous Semantic Grid: Design Architecture of WSDL Parser for Service Oriented Computing," in International Conference on Emerging Technologies, 2006. ICET '06, 2006, pp. 612-616.

[43] J.A. Caicedo and J. C. Corrales, Implementación de un mecanismo de despliegue automático de servicios convergentes en entornos JSLEE. Sistemas \& Telemática, 12(28), 2014, 91-111.

[44] S. Maes, "Understanding the Relationship Between SDP and the Cloud," presented at the CLOUD COMPUTING 2010, The First International Conference on Cloud Computing, GRIDs, and Virtualization, 2010, pp. 159-163.

[45] V. Gonçalves and P. Ballon, "Adding value to the network: Mobile operators' experiments with Software-as-a-Service and Platform-as-aService models," Telematics and Informatics, vol. 28, no. 1, pp. 12-21, Feb. 2011.

[46] M. Taylor, "A Guide to NFV and SDN." 2014. [Online]. Available: http://www. metaswitch.com/sites/default/files/Metaswitch WhitePaper NFVSDN final rs.pdf. [Accessed: 2-Apr-2015].

[47] J. Dugmore and S. Taylor, "ITIL $®$ V3 and ISO/ IEC 20000®", [Online]. Available: http://www. itilnews.com/ITIL_V3 and_ISOIEC_20000. html. [Accessed: 23-Sep-2014].

[48] S. Sesia et al., LTE - The UMTS Long Term Evolution. From Theory to Practice, 2nd Edition. Chippenham, Wiltshire, Great Britain: Wiley, 2011.

[49] C. W. Hsing and C. A. de Souza, "Management practices and influences on IT architecture decisions: a case study in a telecom company," JISTEM - Journal of Information Systems and Technology Management, vol. 9, no. 3, pp. 563-584, Dec. 2012.

[50] N. Kim, R. J. Robles, S. E. Cho, Y. S. Lee and T. Kim, "SOX Act and IT Security Governance," in International Symposium on Ubiquitous Multimedia Computing, 2008. UMC '08, 2008, pp. 218-221.

[51] "Ericsson Mobility Report." Open Article. Ericsson.com, June, 2014. [Online]. Available: http://www.ericsson.com/res/docs/2014/ ericsson-mobility-report-june-2014.pdf. [Accessed: 23-Sep-2014]. 
[52] 3rd Generation Partnership Project; Technical Specification Group Core Network and Terminals; Mobile Application Part (MAP) specification (Release 12), 3GPP TS 29.002 V12.2.0 (2013-09), 2013.

[53] 3rd Generation Partnership Project; Technical Specification Group Core Network and Terminals; Customised Applications for Mobile network Enhanced Logic (CAMEL) Phase 4; CAMEL Application Part (CAP) specification (Release 11), 3GPP TS 29.078 V11.2.0 (201212), 2012.

[54] SIP: Session Initiation Protocol, IETF RFC 3261, 2002.

[55] The Diameter based protocol, IETF RFC 6733, 2012.

[56] Comisión de Regulación de Comunicaciones, República de Colombia. (2013, Oct. 10). Promoción de servicios financieros sobre redes móviles y medidas complementarias para provisión de contenidos y aplicaciones [Online]. Available: http://crcom.gov.co/index. php?idcategoria $=65486 \&$ pag $=2 . \quad$ [Accessed: 23-Sep-2014].

[57] 3rd Generation Partnership Project; Technical Specification Group Core Network and Terminals; Unstructured Supplementary Service Data (USSD); Stage 3 (Release 11), 3GPP TS 24.090 V11.0.0 (2012-09), 2012.

[58] G. Suddul, A. Soobul, U. Bahadoor, A. Ramdoyal, N. Doolhur and M. Richomme, "An Open USSD Enabler to Simplify Access to Mobile Services in Emerging Countries," in 2011 4th International Conference on Emerging
Trends in Engineering and Technology (ICETET), 2011, pp. 323-326.

[59] 3rd Generation Partnership Project; Technical Specification Group Core Network and Terminals; Unstructured Supplementary Service Data (USSD) using IP Multimedia (IM) Core Network (CN) subsystem IMS; Stage 3 (Release 11), 3GPP TS 24.390 V11.5.0 (201406), 2014.

[60] "El Ministerio TIC publica resultados del estudio para la Red Nacional de Telecomunicaciones de Emergencia - Ministerio de Tecnologías de la Información y las Comunicaciones." [Online]. Available: http://www.mintic.gov.co/ portal/604/w3-article-4386.html. [Accessed: 23-Sep-2014].

[61] Ericsson. (2013, January). What is voice over LTE? [Online]. Available: http://www. ericsson.com/res/thecompany/docs/press/ backgrounders/volte_pressbackgrounder.pdf. [Accessed: 23-Sep-2014].

[62] 3rd Generation Partnership Project; Technical Specification Group Core Network and Terminals; Location Services (LCS); Evolved Packet Core (EPC) LCS Protocol (ELP) between the Gateway Mobile Location Centre (GMLC) and the Mobile Management Entity (MME); SLg interface (Release 12), 3GPP TS 29.172 V12.2.0 (2013-09), 2013.

[63] Balefyre. (2013, June). BFDS-20136311/R2 - USSDxTM V.2 [Online]. Available: http:// www.balefyre.co.za/pdfs/ussdx.pdf. [Accessed: 23-Sep-2014]. 